\title{
BELL'S PALSY ASSOCIATED WITH HERPES SIMPLEX VIRUS REACTIVATION DURING PREGNANCY
}

\author{
Kaprelyan A., N. Deleva, Al. Tzoukeva, ${ }^{1}$ Y. Kokareshkova \\ Department of Neurology, Medical University Prof. Dr. P. Stoyanov, \\ ${ }^{1}$ Outpatient Clinic "Sveta Marina"
}

Reviewed by: assoc. prof. Zh. Georgieva

\begin{abstract}
BACKGROUND: Bell's palsy may result from high blood pressure, diabetes, pre-eclampsia, vascular, infectious, genetic, and immunological causes. Accordingly, we present a case of Bell's palsy associated with herpes simplex infection during pregnancy. CASE PRESENTATION: A 33-year-old pregnant woman was admitted to our clinic with sudden onset of inability to close the right eye, excessive tearing, asymmetrical appearance of the mouth, facial twitching, and impaired sense of taste. Medical history revealed an occurrence of herpetic rash around the upper lip one week ago. Checking of facial nerves function recognized unilateral right-sided paralysis. EMG showed severe partial axonal peripheral truncal lesion of the right facial nerve and presence of denervation. The diagnosis was based on patient's history, physical and neurological examination, as well as on laboratory tests and EMG. CONCLUSION: Our case report suggests that the peripheral facial nerve paralysis might be associated with the increased susceptibility to herpes simplex virus infection during pregnancy.
\end{abstract}

Key words: Bell's palsy, pregnancy, herpes simplex virus

\section{BACKGROUND}

Bell's palsy is a unilateral, peripheral facial paresis or paralysis that has a sudden onset $(2,6,12,14,16)$. It accounts approximately $60-75 \%$ of cases with acute unilateral facial damage (13). Although the early description of the syndrome in 1821, the recognition of etiologies and successful management of patients still present a great challenge $(4,11,12,16)$. Data exist that the high blood pressure, diabetes, pre-eclampsia, vascular, infectious, genetic, and immunological causes are most likely associated with this neurological disorder $(1,4,10,11,15,17,18)$. According to the literature, the occurrence of facial nerve paralysis during pregnancy is about three times higher $(3,7,8)$. Idiopathic facial paralysis, although rare, seems to be more frequent during the last trimester of pregnancy or in the early puerperium $(5,9,19)$. We present herein, a case of Bell's palsy induced by herpes simplex virus during the third trimester of pregnancy.

\footnotetext{
Address for correspondence:

A. Kaprelyan, Dept. of Neurology, Prof. P. Stoyanov Medical University, 55 Marin Drinov Street, 9002 Varna, BG,

e-mail: arakapri07@yahoo.co.uk
}

\section{CASE REPORT}

A 33-year-old woman presented to our hospital with sudden onset of inability to close the right eye, excessive tearing, asymmetrical appearance of the mouth, facial twitching, and impaired sense of taste. The patient was pregnant in the third trimester. Medical history revealed an occurrence of herpetic rash around the upper lip one week ago. Checking of facial nerves function recognized complete unilateral right-sided paralysis. Lab results confirmed a high titer of antibodies against herpes simplex virus. EMG showed severe partial axonal peripheral truncal lesion of the right facial nerve and signs of denervation (Fig. 1-6). The diagnosis was based on patient's history, physical and neurological examinations, as well as on laboratory tests and EMG data.

\section{DISCUSSION}

Bell's palsy is the most common acute mononeuropathy, defined in the literature as an idiopathic unilateral facial nerve paralysis $(12,14)$. Several conditions are associated with its development, e.g. brain tumors, stroke, meningitis, cerebral trauma, systemic diseases and viral infections $(1,6,9,11,13,17,19)$. 


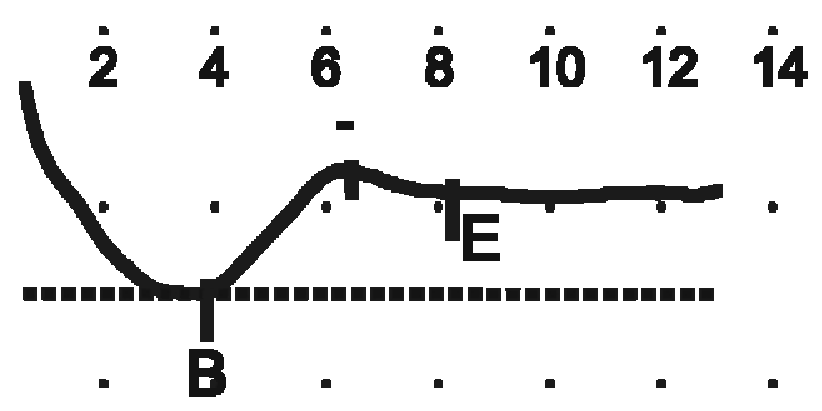

\section{$2 \mathrm{~ms} 1 \mathrm{mV}$}

Fig. 1. Motor CV.

1ch: right, Nasalis, Facialis, Nucl.n.facialis.

$M$-wave amplitude $0.70 \mathrm{mV}$. Terminal latency is $3.8 \mathrm{~ms}$.

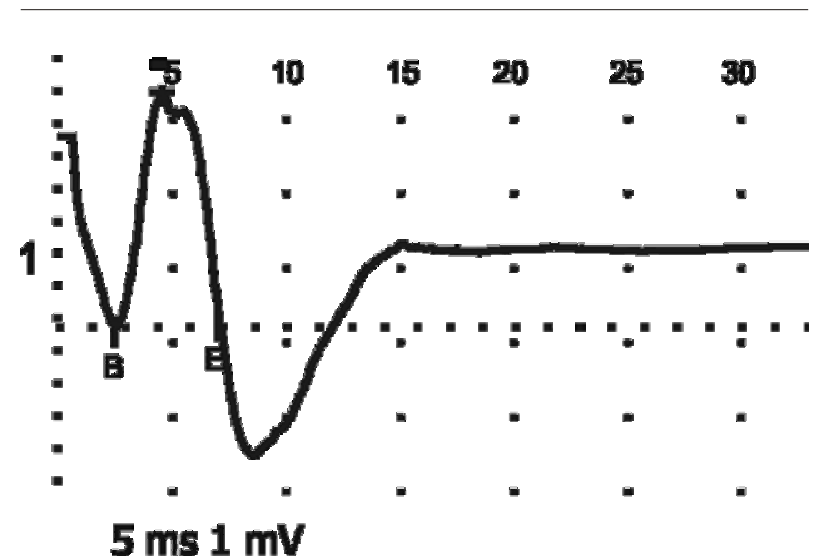

Fig. 3. Motor CV.

1ch: left, Nasalis, Facialis, Nucl.n.facialis.

$M$-wave amplitude $2.14 \mathrm{mV}$. Terminal latency is $2.85 \mathrm{~ms}$.

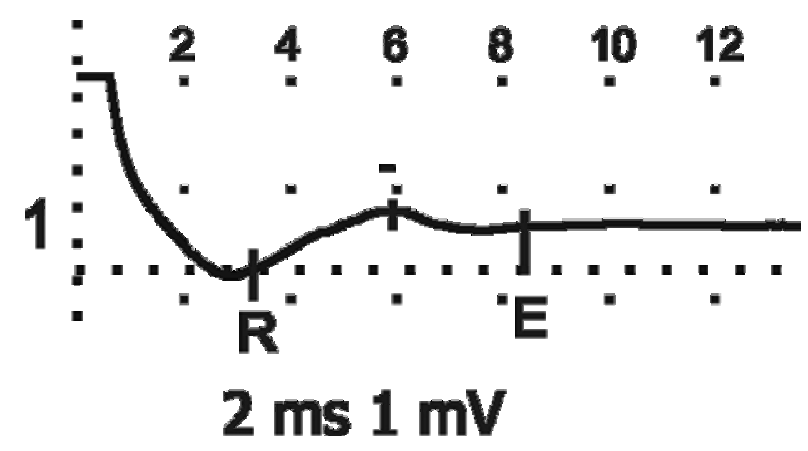

Fig. 2. Motor CV.

1ch: right, Orbicularis oculi, Nucl.n.facialis.

$M$-wave amplitude $0.53 \mathrm{mV}$ (norm 1-3 $\mathrm{mV}$ ). Terminal latency is $3.3 \mathrm{~ms}$.

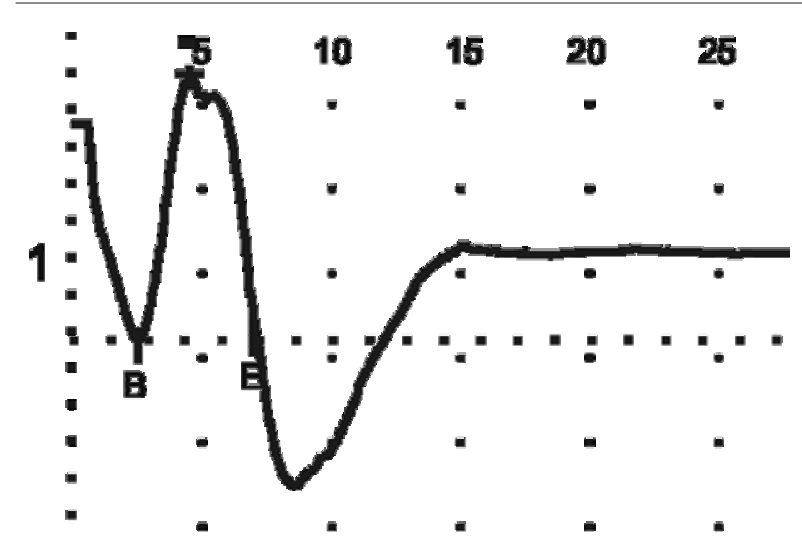

\section{$5 \mathrm{~ms} 1 \mathrm{mV}$}

Fig. 4. Motor CV.

1ch: left, Orbicularis oris, Facialis, Nucl.n.facialis. $M$-wave amplitude $3.11 \mathrm{mV}$ (norm 1-3 $\mathrm{mV}$ ). Terminal latency is $2.5 \mathrm{~ms}$ (norm 2.6-4 $\mathrm{ms}$ ).

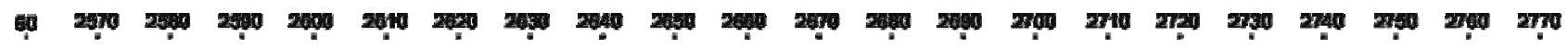

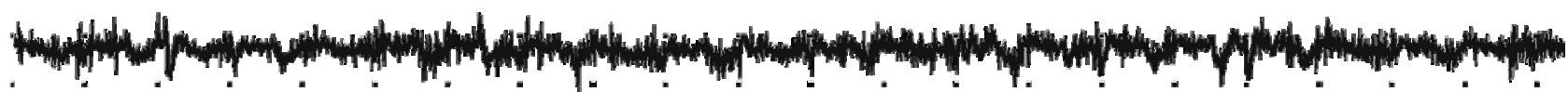

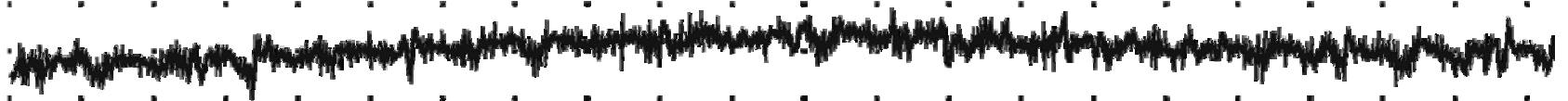

$10 \mathrm{~ms} 50 \mathrm{uV}$

Fig. 5. Needle EMG. Spontaneous activity. 1ch: right, Orbicularis oris, Facialis, Nucl.n.facialis

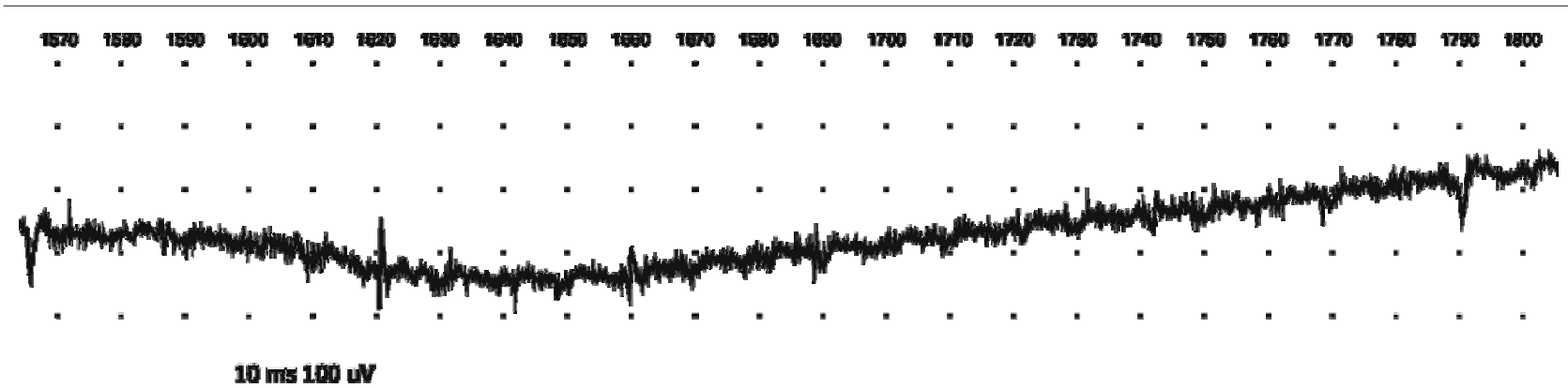

Fig. 6. Needle EMG. Spontaneous activity. 1ch: left, Frontalis, Facialis, Nucl.n.facialis 
Accordingly, we present a case of an acute Bell's palsy in a pregnant woman. Based on the clinical features and performed investigations, we excluded the existence of any specific causes that may induce facial nerve paralysis.

Previous studies reveal that the reactivation of a dormant viral infection may cause an acute Bell's palsy $(4,10,11,15)$. Evidently, the new viral activation could be preceded by various conditions like physical trauma, metabolic or emotional disorders $(3,6,8,12,14)$. Pregnancy is thought to be among these trigger factors $(2,5,7,16,19)$. In accordance with this knowledge, we supposed in our patient a possible causative link between nerve damage and the co-existing viral infection. In this case, the clinical features of herpes infection (herpetic rash) and increased titer of antibodies against varicella simplex virus supported the diagnosis. In comparison to our findings, recent studies also indicate different percentage of patients with underlying herpes zoster, herpes simplex or HIV infections $(3,9,10,18)$.

It is well known that edema, swelling and compression of the nerve in the narrow bone canal are responsible for nerve damage $(12,14)$. Looking through our results and literature review, we discuss the possible role of infectious agent and an unknown immune system response in pathogenesis of virally induced facial nerve paralysis $(4,8,10,11,15,18)$. Obviously, further observations and investigations are necessary to clarify these speculations.

\section{CONCLUSION}

Although the etiology of Bell's palsy often remains unclear and several causes have been proposed, this case presentation confirms that peripheral facial nerve paralysis during pregnancy might be associated with an increased susceptibility to herpes virus infection. Additionally, based on our own notices and literature review, we suggest that the understanding of disease etiology and underlying mechanisms might be useful for both patients' effective treatment and quality of life.

\section{REFERENCES}

1. Alvis J, Hicks R. Pregnancy-induced acute neurologic emergencies and neurologic conditions encountered in pregnancy. Semin Ultrasound CT MR, 2012, 33(1):46-54.

2. Cohen Y., Lavie O., Granovsky-Grisaru S. et al. Bell palsy complicating pregnancy: A Review. Obstetrical \& Gynecological Survey, 2000, 55(3):184-188.

3. Deshpande A. Recurrent Bell's palsy in pregnancy. The Journal of Laryngology \& Otology, 1990, 104:713-714.
4. Furuta Y., Ohtani F., Chida E., et al. Herpes simplex virus type 1 reactivation and antiviral therapy in patients with acute peripheral facial palsy. Auris Nasus Larynx, 2001, 28 (Suppl.1):S13-S17.

5. Gillman G., Schaitkin B., May M., Klein S. Bell's palsy in pregnancy: A study of recovery outcomes. Otolaryngology - Head and Neck Surgery, 2002, 126(1):26-30.

6. Hellebrand M., Friebe-Hoffmann U., Bender H., Kojda G., Hoffmann T. Mona Lisa syndrome: idiopathic facial paralysis during pregnancy. Z Geburtshilfe Neonatol, 2006, 210(4):126-34.

7. Katz A., Sergienko R., Dior U., Wiznitzer A., Kaplan D., Sheiner E. Bell's palsy during pregnancy: is it associated with adverse perinatal outcome? Laryngoscope, 2011, 121(7):1395-8.

8. Ki K., Byun J., Kim S., Song D., Kwon K., Park M. Clinical analysis of Bell's palsy in pregnancy. Korean J Obstet Gynecol, 2009, 52(4):407-412.

9. Kovo M., Sagi Y., Lampl Y., Golan A. Simultaneous bilateral Bell's palsy during pregnancy. $J$ Matern Fetal Neonatal Med, 2009, 22(12):1211-3.

10. Lazarini P, Vianna M., Alcantara M. et al. Herpes simplex virus in the saliva of peripheral Bell's palsy patients. Braz J Otorhinolaryngol, 2006, 72(1):7-11.

11. Linder T., Bossart W., Bodmer D. Bell's palsy and herpes simplex virus: fact or mystery? Otol Neurotol, 2005, 26(1):109-13.

12. Lo B. Bell Palsy. eMedicine, Feb 2010.

13. Monini S., Lazzarino AI., Iacolucci C., Buffoni A., Barbara M. Epidemiology of Bell's palsy in an Italian Health District: incidence and case-control study. Acta Otorhinolaryngol Ital, 2010, 30(4): 198.

14. Ropper A, Samuels M. Bell's palsy section of Diseases of the cranial nerves. In Adams and Victor's Principles of Neurology, $9^{\text {th }}$ ed., New York: McGraw-Hill. 2009, 1330-1331.

15. Schirm J., Mulkens P. Bell's palsy and herpes simplex virus. APMIS, 1997, 105(11):815-23.

16. Shaw M., Nazir F., Bone I. Bell's palsy: a study of the treatment advice given by Neurologists. $J$ Neurol Neurosurg Psychiatry, 2005, 76:293-294.

17. Shmorgun D., Chan W-S., Ray J. Association between Bell's palsy in pregnancy and pre-eclampsia. JMed, 2002, 95:359-362.

18. Stjernquist-Desatnik A., Skoog E., Aurelius E. Detection of herpes simplex and varicella-zoster viruses in patients with Bell's palsy by the polymerase chain reaction technique. Ann Otol Rhinol Laryngol, 2006, 115(4):306-11.

19. Vrabec J., Isaacson B., Van Hook J. Bell's palsy and pregnancy. Otolaryngol Head Neck Surg, 2007, 137(6):858-61. 